\title{
Collision Probabilities, Aircraft Separation and Airways Safety
}

\author{
Luís Campos ${ }^{1,3}$ and Joaquim Marques ${ }^{2,3}$ \\ ${ }^{1}$ Área Científica de Mecânica Aplicada e Aeroespacial (ACMAA), \\ Instituto Superior Técnico (IST), Lisboa, \\ ${ }^{2}$ Faculdade de Ciências Aeronáuticas (FCA), Universidade Lusófona de \\ Humanidades e Tecnologias (ULHT), Lisboa, \\ ${ }^{3}$ Centro de Ciências e Tecnologias Aeronáuticas e \\ Espaciais (CCTAE), Lisboa, \\ Portugal
}

\section{Introduction}

The steady growth of air traffic at a rate of 3-7\% per year over several decades has placed increasing demands on capacity that must be met with undiminished safety (Vismari \& Júnior, 2011). The trend is in fact to improve safety, while meeting more stringent requirements for environment impact, efficiency and cost. The traditional method of safety assurance in Air Traffic Management (ATM) is the setting of separation rules (Houck \& Powell, 2001). The separation distances are determined by: (i) wake vortex effects on approach to land and take-off queues at runways at airports (FAA, 2011; International Civil Aviation Organization [ICAO], 2007; Rossow, 1999); (ii) collision probabilities for the in-flight phases of aircraft operations (Campos \& Marques, 2002; Reich, 1966; Yuling \& Songchen, 2010). Only the latter aspect is considered in the present chapter.

A key aspect of ATM in the future (Eurocontrol, 1998) is to determine (i) the technical requirements to (ii) ensure safety with (iii) increased capacity. The concepts of 'capacity', 'safety' and 'technology' can be given a precise meaning (Eurocontrol, 2000) in the case of airways with aircraft flying on parallel paths with fixed lateral/vertical (Figure 1), or longitudinal (Figure 2) separation: (i) the 'capacity' increases for smaller separation L; (ii) navigation and flight 'technology' should provide a reduced r.m.s. position error $\sigma$; (iii) the combination of $L$ and $\sigma$ should be such that the probability of collision (ICAO, 2006) does not exceed ICAO Target Level of Safety (TLS) of $5 \times 10^{-9}$ per hour (ICAO, 2005). Thus the key issue is to determine the relation between aircraft separation $L$ and position accuracy $\sigma$, which ensures that the ICAO TLS is met. Then the technically achievable position accuracy $\sigma$ specifies $L$, viz. the safe separation distance (SSD). Conversely, if an increase in capacity is sought, the separation $L$ must be reduced; then the ICAO TLS leads to a position accuracy $\sigma$ which must be met by the 'technology'. The position accuracy $\sigma$ includes all causes, e.g. navigation system (Anderson, 1966) error, atmospheric disturbances (Campos, 1984, 1986; Etkin, 1981), inaccuracy of pilot inputs (Campos, 1997; Etkin \& Reid, 1996; Etkin \& Etkin, 1990), etc. 
$\begin{array}{ll}\text { Flight } 1 & \mathrm{a} / \mathrm{c} 1\end{array}$

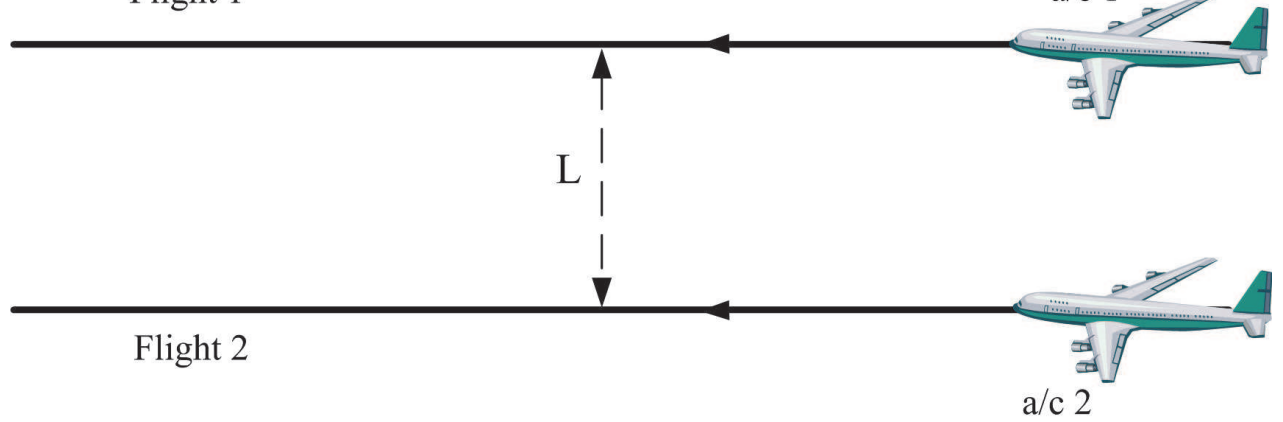

Fig. 1. Aircraft flying always at minimum lateral/vertical separation distance $L$.

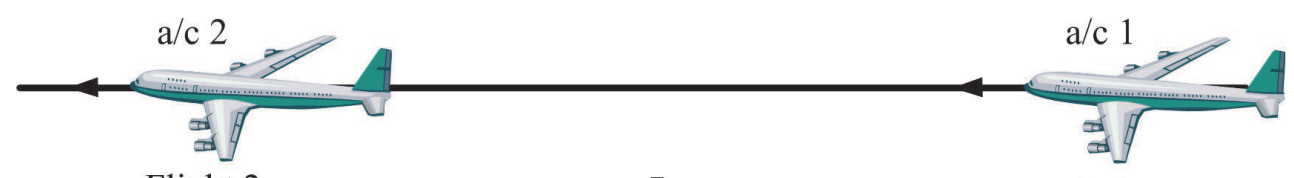

Flight 2

$\mathrm{L}$

Flight 1

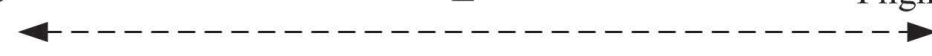

Fig. 2. Aircraft flying always at minimum longitudinal separation distance $L$.

The two main ATM flight scenarios are: (i) parallel paths (Figure 1) with fixed separations in flight corridors typical of transoceanic flight (Bousson, 2008); (ii) crossing (Figure 3) and climbing/descending (Figure 4) flight paths typical of terminal flight operations (Shortle at al., 2010; Zhang \& Shortle, 2010). Since aircraft collisions are rare, two-aircraft events are more likely and this the case considered in the present chapter.

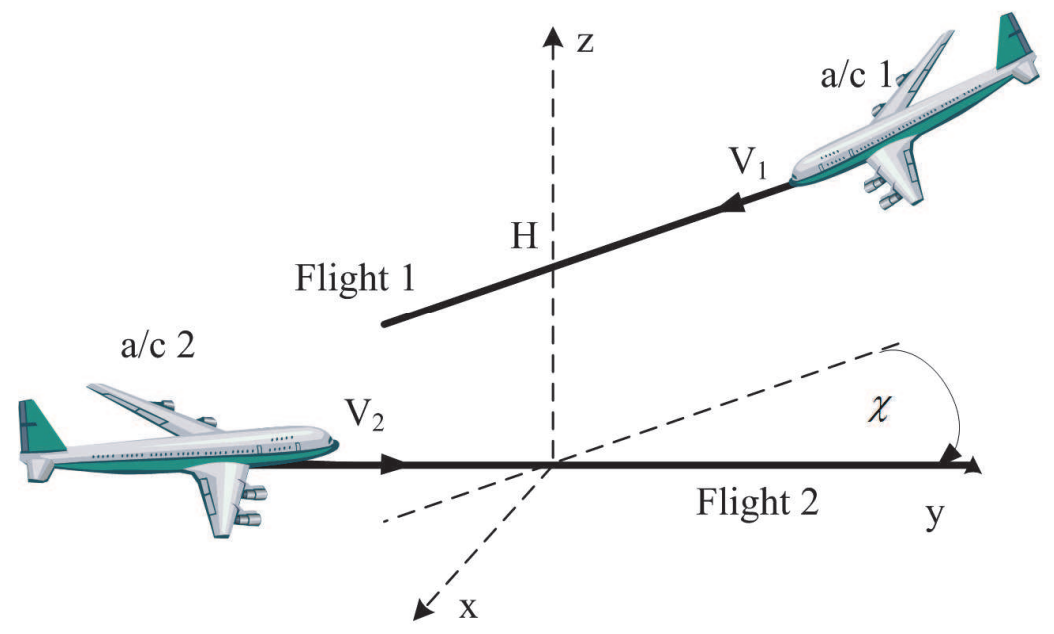

Fig. 3. Geometry of crossing aircraft. 


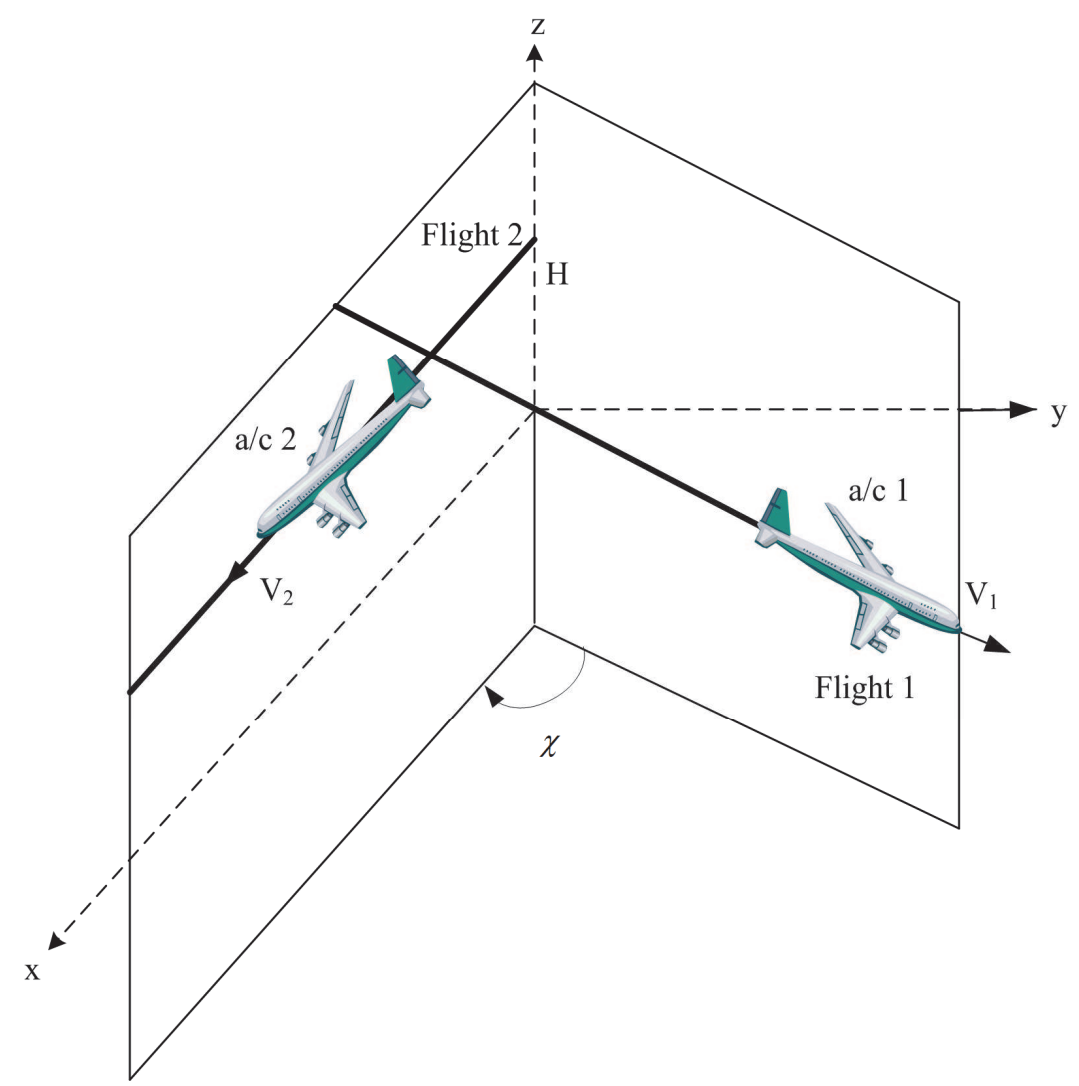

Fig. 4. Geometry of climbing/descending aircraft.

The methods to calculate collision probabilities (Reich, 1966) have been applied to Reduced Vertical Separation Minima (RSVM), to lateral separation (Campos, 2001; Campos \& Marques, 2002), to crossing aircraft (Campos \& Marques, 2007, 2011), to free flight (Barnett, 2000) and to flight in terminal areas (Shortle et al., 2004). The fundamental input to the models of collision probabilities, is the probability distribution (Johnson \& Balakrisshann, 1995; Mises, 1960) of flight path deviations; since it is known that the Gaussian distribution underestimates collision probabilities, and the Laplace distribution though better (Reich, 1966) is not too accurate, the generalized error distribution (Campos \& Marques, 2002; Eurocontrol, 1988), and extensions or combinations have been proposed (Campos \& Marques, 2004a). It can be shown (Campos \& Marques, 2002) that for aircraft on parallel flight corridors (Figure 1) an upper bound to the probability of collision is the probability of coincidence (PC). Its integration along the line joining the two aircraft leads to the cumulative probability of coincidence (CPC); the latter has the dimensions of inverse length, and multiplied by the airspeed, gains the dimensions of inverse time, i.e., can be compared to the ICAO TLS. Alternatively the ICAO TLS can be converted to collision per unit distance, which is directly comparable to the CPC. Since most commercial aircraft fly no faster than $V_{0}=625 \mathrm{kt}$, the ICAO TLS of $P_{0} \leq 5 \times 10^{-9} / \mathrm{h}$, is met by 
$Q_{0}=P_{0} / V_{0} \leq 8 \times 10^{-12} / \mathrm{nm}$. The latter can thus be used as an Alternate Target Level of Safety (ATLS).

In the present chapter the CPC is calculated (Section 2) for comparison with the ICAO ATLS of $8 \times 10^{-12}$ probability of collision per nautical mile; three probability distributions are compared (Section 2.1) and discussed in detail: the Gaussian (Section 2.2); the Laplace (Section 2.3); a generalized error distribution (Section 2.4), which is less simple but more accurate, viz. it has been shown to fit aircraft flight path deviations measured from radar tracks (Campos \& Marques, 2002, 2004a; Eurocontrol, 1988). The comparison of the CPC with the ATLS, is made (Section 3) for four typical cruise flight conditions: (i/ii) lateral separation $L_{a}=50 \mathrm{~nm}$ in uncontrolled (e.g. oceanic) airspace (Section 3.1) and $L_{b}=5 \mathrm{~nm}$ in controlled airspace (Section 3.2); (iii/iv) standard altitude separation $L_{c}=2000 \mathrm{ft}$ used worldwire (Section 3.3) and RVSM $\mathrm{L}_{\mathrm{d}}=1000 \mathrm{ft}$ introduced (figure 5) by Eurocontrol (1988) to increase capacity at higher flight levels (FL290 to FL410). Longitudinal separation along the same flight path could be considered to the limit of wake vortex effects (Campos \& Marques, 2004b; Spalart, 1998). In each of the four cases: (i) the CPC is calculated for several position accuracies $\sigma$, to determine the minimum which meets the safety (ATLS) standard; (ii) the Gauss, Laplace and generalized distributions are compared for the collision probabilities of two aircraft with similar position errors $\sigma$; (iii) the case of aircraft with dissimilar position errors $\sigma_{1}$ and $\sigma_{2}$ is considered from the beginning, and analysed in detail for the most accurate probability distribution. The discussion (Section 4) summarizes the conclusions concerning airways capacity versus position accuracy, for an undiminished safety.

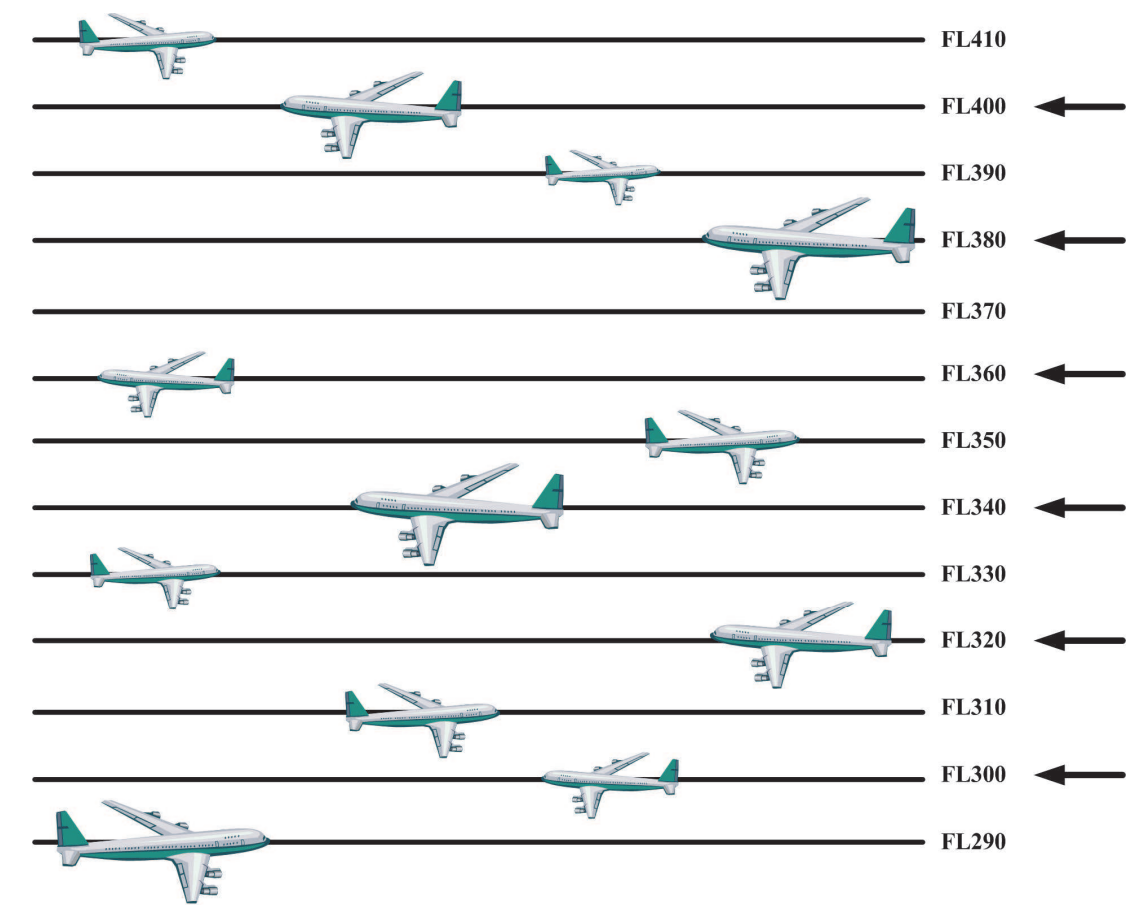

Fig. 5. RVSM between flight levels (FL) 290 and 410 inclusive. 


\section{Comparison of probability distributions for aircraft flight path}

An upper bound for the probability of collision of aircraft on parallel flight tracks (Section 2.1) is calculated using Laplace (Section 2.2), Gaussian (Section 2.3) and generalized (Section 2.4) probability distributions, for aircraft with generally dissimilar r.m.s. position errors.

\subsection{Comparison of three probability distributions for flight path deviations}

Consider two aircraft flying at: (i) either constant lateral or altitude separation $L$ in parallel flight paths (Figure 1), (ii) or at constant longitudinal separation $L$ on the same flight path (Figure 2). In the case of vertical separation there may be an asymmetry in the probability distributions, which has been treated elsewhere (Campos \& Marques, 2007); in the case of longitudinal separation wake effects need to be considered as well (Campos \& Marques, 2004b; Spalart, 1998). Apart from these effects, a class of probability distributions (Johnson \& Balakshishnan, 1995; Mises, 1960) relevant to large aircraft flight deviations (Campos \& Marques, 2002; Eurocontrol, 1998), which are rare events (Reiss \& Thomas, 2001; Nassar et al., 2011), is the generalized error distribution (Campos \& Marques, 2004a), viz.:

$$
F_{k}(x ; \sigma)=A \exp \left(-a|x|^{k}\right)
$$

where $k$ is the weight. The constant $a$ is determined by the condition of unit total probability:

$$
A=k a^{1 / k} /[2 \Gamma(1 / k)],
$$

where $\Gamma(\alpha)$ is the Gamma function of argument $\alpha$. The constant $a$ can be related by:

$$
a^{2 / k}=\sigma^{-2}[\Gamma(3 / k) / \Gamma(1 / k)]
$$

to the r.m.s. position error $\sigma$ or variance $\sigma^{2}$. The case of weight unity in $(2 \mathrm{a}, \mathrm{b})$, viz.:

$$
k=1: \quad a=\sqrt{2} / \sigma, \quad A=1 /(\sigma \sqrt{2}),
$$

corresponds by (1) to the Laplace probability distribution:

$$
F_{1}(x ; \sigma)=[1 /(\sigma \sqrt{2})] \exp (-\sqrt{2}|x| / \sigma) ;
$$

the case of weight two in $(2 a, b)$, viz.:

$$
k=2: \quad a=1 /\left(2 \sigma^{2}\right), \quad A=2 /(\sigma \sqrt{2 \pi}),
$$

leads by (1) to the Gaussian probability distribution:

$$
F_{2}(x ; \sigma)=[1 /(\sigma \sqrt{2 \pi})] \exp \left[-x^{2} /\left(2 \sigma^{2}\right)\right]
$$

the best approximation to large aircraft flight path deviations (Campos \& Marques, 2002, 2007; Campos, 2001) corresponds approximately to weight one-half, so that $(2 \mathrm{a}, \mathrm{b})$ : 


$$
k=1 / 2: \quad a^{4}=120 / \sigma^{2}, \quad A=\sqrt{15 / 2} / \sigma,
$$

substituted in (1) leads to:

$$
F_{1 / 2}(x ; \sigma)=(\sqrt{15 / 2} / \sigma) \exp \left(-\sqrt[4]{120}|x / \sigma|^{1 / 2}\right),
$$

which may be designated for brevity the 'generalized' distribution. For any probability distribution, it can be shown (Campos \& Marques, 2002) that an upper bound for the probability of collision is the probability of coincidence, which (Figure 6): implies (i) a deviation for the first aircraft, with r.m.s. position error $\sigma_{1}$; (ii) a deviation $L-x$ for the second aircraft error $\sigma_{2}$.

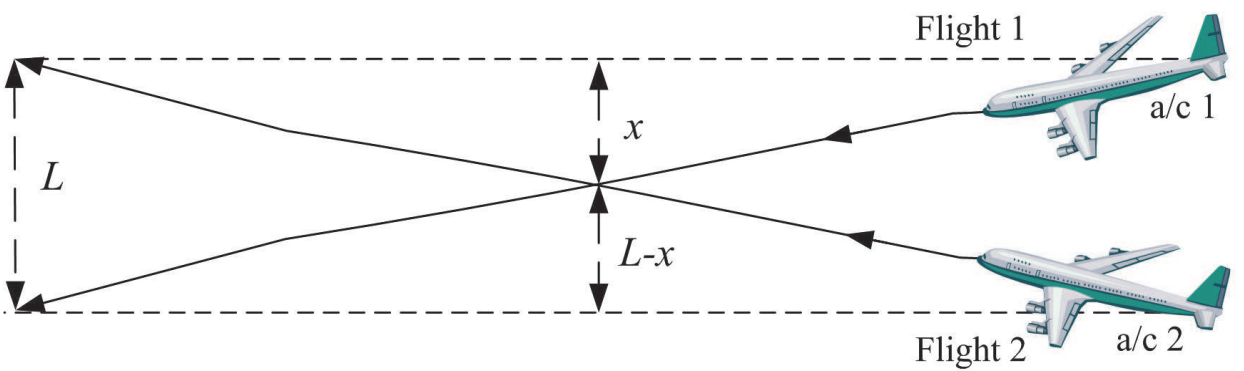

Fig. 6. Aircraft flying on parallel paths: a coincidence will occur if position errors are $x$ (aircraft 1) and L-x (aircraft 2).

For statistically independent aircraft deviations, the probability of coincidence at position $x$ the product:

$$
P_{k}\left(x ; L, \sigma_{1}, \sigma_{2}\right)=F_{k}\left(x ; \sigma_{1}\right) F_{k}\left(L-x ; \sigma_{2}\right) .
$$

Its integral over all positions along the line joining the two aircraft is the CPC, viz.:

$$
Q_{k}\left(L ; \sigma_{1}, \sigma_{2}\right)=\int_{-\infty}^{+\infty} P_{k}\left(x ; L, \sigma_{1}, \sigma_{2}\right) d x=\int_{-\infty}^{+\infty} F_{k}\left(x ; \sigma_{1}\right) F_{k}\left(L-x ; \sigma_{2}\right) d x,
$$

and, in particular, for aircraft with equal r.m.s. position errors:

$$
\sigma \equiv \sigma_{1}=\sigma_{2}: \quad Q_{k}(L ; \sigma) \equiv Q_{k}(L ; \sigma, \sigma)=\int_{-\infty}^{+\infty} F_{k}(x ; \sigma) F_{k}(L-x ; \sigma) d x .
$$

The CPC has the dimensions of inverse length. The ICAO TLS of $5 \times 10^{-9} / \mathrm{h}$ (12a) can be converted for a maximum airspeed $V_{0}=625 \mathrm{kt}$ in (12b) to a ATLS given:

$$
\bar{Q}_{0}=5 \times 10^{-9} h^{-1}, \quad V_{0} \leq 625 k t, \quad Q \leq Q_{0}=\bar{Q}_{0} / V_{0} \leq 8 \times 10^{-12} \mathrm{~nm}^{-1},
$$

which is an upper bound for the CPC. The safety criterion (12c) is applied next to the Laplace (Section 2.2), Gaussian (Section 2.3) and generalized (Section 2.4) probability density functions. 


\subsection{Laplace distributions for the dissimilar aircraft}

The ATLS (12c) is the upper bound for the CPC (10) calculated for aircraft whose position errors follow the Laplace probability distribution (4), with dissimilar r.m.s. position errors for the two aircraft:

$$
Q_{0} \geq Q_{1}\left(L ; \sigma_{1}, \sigma_{2}\right)=\left[1 /\left(2 \sigma_{1} \sigma_{2}\right)\right] \int_{-\infty}^{+\infty} \exp \left[-\sqrt{2}\left(|x| / \sigma_{1}+|L-x| / \sigma_{2}\right)\right] d x .
$$

The appearance of modulus in the argument of the exponential in (13), requires that the range of integration $-\infty,+\infty$ be split in three parts. The first part corresponds to coincidence at $0 \leq x \leq L$ between the flight paths of the two aircraft:

$$
\begin{aligned}
2 \sigma_{1} \sigma_{2} Q_{11} & =\int_{0}^{L} \exp \left[-\sqrt{2}\left(x / \sigma_{1}+(L-x) / \sigma_{2}\right)\right] d x= \\
& =\exp \left(-\sqrt{2} L / \sigma_{2}\right) \int_{0}^{L} \exp \left[-\sqrt{2} x\left(1 / \sigma_{1}-1 / \sigma_{2}\right)\right] d x,
\end{aligned}
$$

and involves an elementary integration:

$$
2 \sigma_{1} \sigma_{2} Q_{11}=\exp \left(-\sqrt{2} L / \sigma_{2}\right)\left\{1-\exp \left[-\sqrt{2} L\left(1 / \sigma_{1}-1 / \sigma_{2}\right)\right]\right\}\left[\sqrt{2}\left(1 / \sigma_{1}-1 / \sigma_{2}\right)\right]^{-1},
$$

and simplifies to:

$$
Q_{11}=\left[2 \sqrt{2}\left(\sigma_{2}-\sigma_{1}\right)\right]^{-1}\left[\exp \left(-\sqrt{2} L / \sigma_{2}\right)-\exp \left(-\sqrt{2} L / \sigma_{1}\right)\right],
$$

and should be the main contribution (i) to (13). To evaluate (13) exactly, the remaining contributions, besides (i), are also considered: (ii) the coincidence at a point $x \geq L$ outside the path of second aircraft:

$$
2 \sigma_{1} \sigma_{2} Q_{12}=\int_{L}^{\infty} \exp \left\{-\sqrt{2}\left[x / \sigma_{1}+(x-L) / \sigma_{2}\right]\right\} d x,
$$

leads to an elementary integral:

$$
\begin{aligned}
& 2 \sigma_{1} \sigma_{2} Q_{12}=\exp \left(\sqrt{2} L / \sigma_{2}\right) \int_{L}^{\infty} \exp \left\{-\sqrt{2} x\left(1 / \sigma_{1}+1 / \sigma_{2}\right)\right\} d x \\
& =\exp \left(\sqrt{2} L / \sigma_{2}\right)\left[\sqrt{2}\left(1 / \sigma_{1}+1 / \sigma_{2}\right)\right]^{-1} \exp \left[-\sqrt{2} L\left(1 / \sigma_{1}+1 / \sigma_{2}\right)\right],
\end{aligned}
$$

which simplifies to:

$$
Q_{12}=\left[2 \sqrt{2}\left(\sigma_{1}+\sigma_{2}\right)\right]^{-1} \exp \left(-\sqrt{2} L / \sigma_{1}\right) ;
$$

(iii) the coincidence $-\infty<x<0$ outside the flight path of the first aircraft:

$$
\begin{aligned}
& 2 \sigma_{1} \sigma_{2} Q_{13}=\int_{-\infty}^{0} \exp \left\{\sqrt{2}\left[x / \sigma_{1}-(L-x) / \sigma_{2}\right]\right\} d x \\
& =\exp \left(-\sqrt{2} L / \sigma_{2}\right) \int_{0}^{\infty} \exp \left\{-\sqrt{2} x\left(1 / \sigma_{1}+1 / \sigma_{2}\right)\right\} d x,
\end{aligned}
$$


is again an elementary integral:

$$
Q_{13}=\left[2 \sqrt{2}\left(\sigma_{2}+\sigma_{1}\right)\right]^{-1} \exp \left(-\sqrt{2} L / \sigma_{2}\right) .
$$

The sum of (21), (19) and (16) specifies the CPC where:

$$
\begin{aligned}
& Q_{1}\left(L ; \sigma_{1}, \sigma_{2}\right)=\left[2 \sqrt{2}\left(\sigma_{2}-\sigma_{1}\right)\right]^{-1}\left[\exp \left(-\sqrt{2} L / \sigma_{2}\right)-\exp \left(-\sqrt{2} L / \sigma_{1}\right)\right] \\
& +\left[2 \sqrt{2}\left(\sigma_{2}+\sigma_{1}\right)\right]^{-1}\left[\exp \left(-\sqrt{2} L / \sigma_{1}\right)+\exp \left(-\sqrt{2} L / \sigma_{2}\right)\right],
\end{aligned}
$$

for the Laplace distribution:

$$
Q_{1}\left(L ; \sigma_{1}, \sigma_{2}\right)=Q_{11}+Q_{12}+Q_{13} \leq Q_{0}=8 \times 10^{-12} n m^{-1} ，
$$

and hence (12c) the safety criterion. Of the preceding expressions, only (16) breaks down for $\sigma_{2}-\sigma_{1}=0$, i.e., aircraft with the same r.m.s. position error $\sigma_{1}=\sigma_{2} \equiv \sigma$. In this case the probability of coincidence is given: (i) between the flight paths of the two aircraft, instead of (14-16) by:

$$
\sigma_{1}=\sigma_{2} \equiv \sigma: \quad \bar{Q}_{11}=\left(2 \sigma^{2}\right)^{-1} \int_{0}^{L} \exp (-\sqrt{2} L / \sigma) d x=\left[L /\left(2 \sigma^{2}\right)\right] \exp (-\sqrt{2} L / \sigma)
$$

(ii) outside the flight path of the second aircraft (17-19) is replaced by:

$$
\begin{aligned}
\sigma_{1}=\sigma_{2} \equiv \sigma: \quad \bar{Q}_{12} & =\left(2 \sigma^{2}\right)^{-1} \exp (\sqrt{2} L / \sigma) \int_{L}^{\infty} \exp (-2 \sqrt{2} x / \sigma) d x \\
& =(4 \sqrt{2} \sigma)^{-1} \exp (-\sqrt{2} L / \sigma) ;
\end{aligned}
$$

(iii) outside the flight path of the second aircraft (20-22) is replaced by:

$$
\begin{gathered}
\sigma_{1}=\sigma_{2} \equiv \sigma: \quad \bar{Q}_{13}=\left(2 \sigma^{2}\right)^{-1} \exp (-\sqrt{2} L / \sigma) \int_{-\infty}^{0} \exp (2 \sqrt{2} x / \sigma) d x \\
=(4 \sqrt{2} \sigma)^{-1} \exp (-\sqrt{2} L / \sigma) .
\end{gathered}
$$

The sum of (23), (24) and (25) specifies:

$$
Q_{1}(L ; \sigma)=\exp (-\sqrt{2} L / \sigma)(2 \sigma)^{-1}(L / \sigma+1 / \sqrt{2}),
$$

as the safety criterion:

$$
\sigma_{1}=\sigma_{2} \equiv \sigma: \quad Q_{1}(L ; \sigma)=\bar{Q}_{11}+\bar{Q}_{12}+\bar{Q}_{13} \leq Q_{0}=8 \times 10^{-12} n^{-1},
$$

for Laplace probabilities with equal r.m.s. position errors for both aircraft.

\subsection{Gaussian distribution with distinct variances}

The ATLS (12c) is the upper bound for the CPC (10) calculated next for aircraft whose flight path deviations satisfy the Gaussian probability distribution (6) for aircraft with dissimilar variances of position errors: 


$$
Q_{0} \geq Q_{2}\left(L ; \sigma_{1}, \sigma_{2}\right)=\left(2 \pi \sigma_{1} \sigma_{2}\right)^{-1} \int_{-\infty}^{+\infty} \exp \left\{-\left[\left(x / \sigma_{1}\right)^{2}+\left((L-x) / \sigma_{2}\right)^{2}\right] / 2\right\} d x .
$$

The integral in (27) does not need splitting to be evaluated, e.g. in the case of equal variances:

$$
\begin{array}{r}
\sigma_{1}=\sigma_{2} \equiv \sigma: \quad Q_{0} \geq Q_{2}(L ; \sigma)=\left(2 \pi \sigma^{2}\right)^{-1} \int^{+\infty} \exp \left\{-\left[x^{2}+(L-x)^{2}\right] /\left(2 \sigma^{2}\right)\right\} d x \\
=\left(2 \pi \sigma^{2}\right)^{-1} \exp \left[-L^{2} / 2 \sigma^{2}\right] \int_{-\infty}^{+\infty} \exp \left\{-\left(x^{2}-x L\right) / \sigma^{2}\right\} d x
\end{array}
$$

the change of variable (29a):

$$
y=(x-L / 2) / \sigma: \quad \int_{-\infty}^{+\infty} \exp \left(-y^{2}\right) d y=\sqrt{\pi},
$$

leads to a Gaussian integral (29b), viz.:

$$
Q_{2}(L ; \sigma)=\left(2 \pi \sigma^{2}\right)^{-1} \exp \left[-L^{2} /\left(2 \sigma^{2}\right)\right] \int_{-\infty}^{+\infty} \exp \left(-y^{2}+L^{2} / 4 \sigma^{2}\right) d y
$$

using $(29 b)$ in (30) leads to:

$$
Q_{2}(L ; \sigma)=\left(2 \sqrt{\pi} \sigma^{2}\right)^{-1} \exp \left[-(L / 2 \sigma)^{2}\right] \leq Q_{0}=8 \times 10^{-12} n m^{-1},
$$

as the safety criterion.

In the more general case (27) of aircraft with dissimilar r.m.s. position errors:

$$
Q_{2}=\left(2 \pi \sigma_{1} \sigma_{2}\right)^{-1} \exp \left(-L^{2} \sigma_{2}^{-2} / 2\right) \int_{-\infty}^{+\infty} \exp \left\{-\left[\left(x^{2} / 2\right)\left(\sigma_{1}^{-2}+\sigma_{2}^{-2}\right)-x L \sigma_{2}^{-2}\right]\right\} d x,
$$

the change of variable:

$$
y=\left[x \sqrt{\sigma_{1}^{-2}+\sigma_{2}^{-2}}-L \sigma_{2}^{-2} / \sqrt{\sigma_{1}^{-2}+\sigma_{2}^{-2}}\right] / \sqrt{2},
$$

leads again to a Gaussian integral (29b), viz.:

$$
Q_{2}=\left(2 \pi \sigma_{1} \sigma_{2}\right)^{-1} \exp \left(-L^{2} \sigma_{2}^{-2} / 2\right) \exp \left\{L^{2} \sigma_{2}^{-4} /\left[2\left(\sigma_{1}^{-2}+\sigma_{2}^{-2}\right)\right]\right\} \int_{-\infty}^{+\infty} \exp \left(-y^{2}\right) d y,
$$

which simplifies the safety condition to:

$$
Q_{0} \geq Q_{2}\left(L ; \sigma_{1}, \sigma_{2}\right)=\left(2 \sqrt{\pi} \sigma_{1} \sigma_{2}\right)^{-1} \exp \left\{-\left(L^{2} / 2\right) /\left[\left(\sigma_{1}\right)^{2}+\left(\sigma_{2}\right)^{2}\right]\right\} .
$$

This reduces to (31) in the case of equal r.m.s. position errors. 


\subsection{Generalized error or Gaussian distribution}

The safety condition (12c) for (10) the more accurate (8) generalized probability distribution:

$$
\begin{aligned}
& c \equiv \sqrt[4]{120}: \\
& Q_{0} \geq Q_{3}\left(L ; \sigma_{1}, \sigma_{2}\right)=\left[15 /\left(2 \sigma_{1} \sigma_{2}\right)\right] \int_{-\infty}^{+\infty} \exp \left\{-c\left[\left|x / \sigma_{1}\right|^{1 / 2}+\left|(L-x) / \sigma_{2}\right|^{1 / 2}\right]\right\} d x,
\end{aligned}
$$

requires again a split in the region of integration as for the Laplace distribution (Section 2.2), with the difference that the evaluation of integrals is not elementary. The contribution to the cumulative probability of coincidence of the position between the flight paths of the two aircraft is:

$$
\begin{gathered}
Q_{31}=\left[\left(15 / 2 \sigma_{1} \sigma_{2}\right)\right] \int_{0}^{L} \exp \left\{-c\left[\sqrt{x / \sigma_{1}}+\sqrt{(L-x) / \sigma_{2}}\right]\right\} d x, \\
=\frac{15}{2 \sigma_{1} \sigma_{2}} \sum_{n=0}^{\infty} \frac{(-)^{n} c^{n}}{n !} \int_{0}^{L}\left\{\sqrt{x / \sigma_{1}}+\sqrt{(L-x) / \sigma_{2}}\right\}^{n} d x,
\end{gathered}
$$

where the exponential was expanded in power series, and binomial theorem:

$$
\left[\sqrt{x / \sigma_{1}}+\sqrt{(L-x) / \sigma_{2}}\right]^{n}=\sum_{m=0}^{n}\{n ! /[m !(n-m) !]\}\left(x / \sigma_{1}\right)^{m / 2}\left[(L-x) / \sigma_{2}\right]^{(n-m) / 2},
$$

can also be used:

$$
Q_{31}=\frac{15}{2 \sigma_{1} \sigma_{2}} \sum_{n=0}^{\infty} \sum_{m=0}^{n} \frac{(-)^{n} c^{n}}{m !(n-m) !} \sigma_{1}^{-m / 2} \sigma_{2}^{-(n-m) / 2} \mathrm{I}_{n, m},
$$

and $\mathrm{I}_{n, m}$ denotes the integral:

$$
\mathrm{I}_{n, m} \equiv \int_{0}^{L} x^{m / 2}(L-x)^{(n-m) / 2} d x,
$$

which can be reduced to an Euler's Beta function. The Beta function (40a) is defined (Whittaker \& Watson, 1927) by:

$$
B(\alpha, \beta) \equiv \int_{0}^{1} y^{\alpha-1}(1-y)^{\beta-1} d y=\Gamma(\alpha) \Gamma(\beta) / \Gamma(\alpha+\beta),
$$

and can be evaluated (40b) in terms of Gamma functions (Goursat, 1950). The integrals (39b) are evaluated in terms of the Beta function via a change of variable.

$$
\begin{aligned}
& y \equiv x / L: \\
& \begin{aligned}
L^{-1-n / 2} \mathrm{I}_{n m}=\int_{0}^{1} y^{m / 2}(1-y)^{(n-m) / 2} d y & =B(1+m / 2,1+(n-m) / 2) \\
& =\Gamma(1+m / 2) \Gamma(1+(n-m) / 2) / \Gamma(2+n / 2) .
\end{aligned}
\end{aligned}
$$


Substitution of (41c) in (39a) yields:

$$
Q_{31}=\frac{15 L}{2 \sigma_{1} \sigma_{2}} \sum_{n=0}^{\infty} \sum_{m=0}^{n} \frac{(-)^{n} c^{n}}{m !(n-m) !}\left(\frac{L}{\sigma_{1}}\right)^{m / 2}\left(\frac{L}{\sigma_{2}}\right)^{(n-m) / 2} \frac{\Gamma(1+m / 2) \Gamma(1+n / 2-m / 2)}{\Gamma(2+n / 2)}
$$

as the first contribution to (36).

Since (42) may be expected to be the main contribution to (36), we seek upper bounds for the two remaining contributions. The second contribution to (36) concerns coincidence outside the path of the second aircraft:

$$
Q_{32}=\left[15 /\left(2 \sigma_{1} \sigma_{2}\right)\right] \int_{L}^{\infty} \exp \left\{-c\left[\sqrt{x / \sigma_{1}}+\sqrt{(x-L) / \sigma_{2}}\right]\right\} d x
$$

an upper bound is obtained by replacing $x \geq L$ by $L$ in the first exponential:

$$
Q_{32} \leq\left[15 /\left(2 \sigma_{1} \sigma_{2}\right)\right] \exp \left(-c \sqrt{L / \sigma_{1}}\right) \int_{L}^{\infty} \exp \left[-c \sqrt{(x-L) / \sigma_{2}}\right] d x,
$$

the change of variable (44a) leads:

$$
y=c \sqrt{(x-L) / \sigma_{2}}, \quad Q_{32} \leq \frac{15}{\sigma_{1} c^{2}} \exp \left(-c \sqrt{L / \sigma_{1}}\right) \int_{0}^{\infty} e^{-y} y d y,
$$

to an integral (44b) which is evaluated in terms (Whittaker \& Watson, 1927; Goursat, 1950) of the Gamma function:

$$
\int_{0}^{\infty} e^{-y} y^{n} d y=\Gamma(n+1) \equiv n !
$$

using (45a) in (44b) leads to the upper bound for the second contribution to (36), viz.:

$$
Q_{32} \leq\left[15 /\left(\sigma_{1} c^{2}\right)\right] \exp \left(-c \sqrt{L / \sigma_{1}}\right) .
$$

The third contribution to (36) corresponds to coincidence outside the flight path of the first aircraft:

$$
\begin{aligned}
& Q_{33}=\left[15 /\left(2 \sigma_{1} \sigma_{2}\right)\right] \int_{-\infty}^{0} \exp \left\{-c\left[\sqrt{-x / \sigma_{1}}+\sqrt{(L-x) / \sigma_{2}}\right]\right\} d x \\
& =\left[15 /\left(2 \sigma_{1} \sigma_{2}\right)\right] \int_{0}^{\infty} \exp \left(-c \sqrt{x / \sigma_{1}}\right) \exp \left(-c \sqrt{(L+x)} / \sigma_{2}\right) d x
\end{aligned}
$$

an upper bound is obtained by replacing in the second exponential $L+x \geq L$ by $L$ :

$$
Q_{33} \leq\left[15 /\left(2 \sigma_{1} \sigma_{2}\right)\right] \exp \left(-c \sqrt{L / \sigma_{2}}\right) \int_{0}^{\infty} \exp \left(-c \sqrt{x / \sigma_{1}}\right) d x
$$


The last integral is evaluated via a change of variable:

$$
y=c \sqrt{x / \sigma_{1}}: \quad Q_{33} \leq\left[15 /\left(\sigma_{2} c^{2}\right)\right] \exp \left(-c \sqrt{L / \sigma_{2}}\right) \int_{0}^{\infty} e^{-y} y d y,
$$

leading by (45a) to:

$$
Q_{33} \leq\left[15 /\left(\sigma_{2} c^{2}\right)\right] \exp \left(-c \sqrt{L / \sigma_{2}}\right) .
$$

If the upper bounds (45b) and (47b) are small relative to the first contribution (42) to (36), viz.:

$$
Q_{31}>>\left(15 / c^{2}\right)\left[\sigma_{1}^{-1} \exp \left(-c \sqrt{L / \sigma_{1}}\right)+\sigma_{2}^{-1} \exp \left(-c \sqrt{L / \sigma_{2}}\right)\right] \geq Q_{32}+Q_{33} ，
$$

then (46) alone can be used in the safety criterions (12c), viz.:

$$
8 \times 10^{-12} \mathrm{~nm}^{-1}=Q_{0} \geq Q_{31},
$$

with an error whose upper bound is specified by the ratio of the r.h.s. to 1.h.s. of (48a). If the latter error is not acceptable, then (43a) and (46b) must be evaluated exactly. Concerning the second contribution (43a) to (36), the change of variable (49a):

$$
x=L \cosh ^{2} \alpha, \quad x-L=L \sinh ^{2} \alpha,
$$

implies (49b), and transforms (43a) to:

$$
Q_{32}=\left[15 L /\left(\sigma_{1} \sigma_{2}\right)\right] \int_{0}^{\infty} d \alpha \cosh \alpha \sinh \alpha \exp \left\{-c \sqrt{L}\left(\sigma_{1}^{-1 / 2} \cosh \alpha+\sigma_{2}^{-1 / 2} \sinh \alpha\right) .\right.
$$

Concerning the third contribution (46b) to (36) the change or variable (50a):

$$
x=L \sinh ^{2} \alpha, \quad x+L=L \cosh ^{2} \alpha,
$$

implies (50b), and leads to:

$$
Q_{33}=\left[15 L /\left(\sigma_{1} \sigma_{2}\right)\right] \int_{0}^{\infty} d \alpha \sinh \alpha \cosh \alpha \exp \left\{-c \sqrt{L}\left(\sigma_{1}^{-1 / 2} \sinh \alpha+\sigma_{2}^{-1 / 2} \cosh \alpha\right)\right\},
$$

which is similar to (49c) interchanging $\sigma_{1}$ with $\sigma_{2}$. The integrals (49c) and (50c) can be evaluated numerically, and coincide in the case of equal r.m.s. position errors:

$$
\sigma_{1}=\sigma_{2} \equiv \sigma: \quad Q_{32}=Q_{33}=\frac{15 L}{4 \sigma^{2}} \int_{0}^{\infty} \exp \left(-c \sqrt{L / \sigma} e^{\alpha}\right)\left(e^{2 \alpha}-e^{-2 \alpha}\right) d \alpha .
$$

A further change of variable (51b) yields:

$$
\begin{aligned}
& y=c \sqrt{L / \sigma} e^{\alpha}: \\
& Q_{32}+Q_{33}=\frac{15 L}{2 \sigma^{2}} \int_{c \sqrt{L / \sigma}}^{\infty} e^{-y}\left\{\left[\sigma /\left(c^{2} L\right)\right] y-\left(c^{2} L / \sigma\right) y^{-3}\right] d y .
\end{aligned}
$$


The exponential integral of order $n$ is defined (Abramowitz \& Stegun, 1965) by:

$$
E_{n}(z)=\int_{z}^{\infty} y^{n} e^{-y} d y
$$

and allows evaluation of (51b), viz.:

$$
Q_{32}+Q_{33}=\left[15 L /\left(2 \sigma^{2}\right)\right]\left\{\left[\sigma /\left(c^{2} L\right)\right] E_{1}(c \sqrt{L / \sigma})-\left[\left(c^{2} L\right) / \sigma\right] E_{-3}(c \sqrt{L / \sigma})\right\} .
$$

The sum of the three contributions (42) plus (49c) and (50c) or (52b), specifies:

$$
8 \times 10^{-12} \mathrm{~nm}^{-1}=Q_{0} \geq Q_{3}\left(L ; \sigma_{1}, \sigma_{2}\right)=Q_{31}+Q_{32}+Q_{33} ，
$$

as the safety condition.

\section{Application to four ATM scenarios}

The preceding safety-separation criteria are applied to the four major airway scenarios, viz. lateral separation in uncontrolled (Section 3.1) and controlled (Section 3.2) airspace and standard (Section 3.3) and reduced (Section 3.4) vertical separation.

\begin{tabular}{|c|c||c|c|c|}
\hline \multicolumn{2}{|c||}{ Probability distribution } & Laplace & Gauss & Generalized \\
\hline quantity & $\sigma_{a}$ & $Q_{1 a}$ & $Q_{2 a}$ & $Q_{3 a}$ \\
\hline Unit & $\mathrm{nm}$ & - & - & - \\
\hline \hline 10 & $\mathrm{~nm}$ & $2,42 \mathrm{E}-04$ & $5,45 \mathrm{E}-06$ & $3,80 \mathrm{E}-04$ \\
\hline 5 & $\mathrm{~nm}$ & $7,72 \mathrm{E}-07$ & $1,57 \mathrm{E}-13$ & $3,58 \mathrm{E}-05$ \\
\hline 4 & $\mathrm{~nm}$ & $3,47 \mathrm{E}-08$ & $1,91 \mathrm{E}-19$ & $1,28 \mathrm{E}-05$ \\
\hline 3 & $\mathrm{~nm}$ & $1,68 \mathrm{E}-10$ & $2,17 \mathrm{E}-32$ & $2,75 \mathrm{E}-06$ \\
\hline 2 & $\mathrm{~nm}$ & $2,84 \mathrm{E}-15$ & $9,77 \mathrm{E}-70$ & $1,92 \mathrm{E}-07$ \\
\hline 1 & $\mathrm{~nm}$ & $4,95 \mathrm{E}-30$ & $1,04 \mathrm{E}-272$ & $3,88 \mathrm{E}-10$ \\
\hline 0,5 & $\mathrm{~nm}$ & $3,84 \mathrm{E}-60$ & $0,00 \mathrm{E}-00$ & $4,70 \mathrm{E}-14$ \\
\hline
\end{tabular}

Table 1. Lateral $a$ CPC for the Laplace, Gaussian and generalized probabilities.

\subsection{Lateral separation in oceanic airspace}

The lateral separation in oceanic airspace is (53a):

$$
L_{a}=50 \mathrm{~nm}, \quad \sigma_{a}=0.5,1.0,2.0,3.0,4.0,5.0,10, \mathrm{~nm},
$$

and the r.m.s. position error is given the values (53b) in Table 1, where the CPC are indicated for the Laplace, Gaussian and generalized probabilities. Taking as reference the generalized probability distribution, that is the most accurate representation of large flight 
path deviation considerably underestimates the risk of collision, and the Laplace distribution although underestimating less is still not safe. For example the ICAO ATLS of $8 \times 10^{-12} / \mathrm{nm}$ is met according to the generalized probability distribution for a r.m.s. position deviation $\sigma_{a} \leq 1 \mathrm{~nm}$; the Laplace distribution would give $\sigma_{a} \leq 3 \mathrm{~nm}$ and the Gaussian $\sigma_{a} \leq 5 \mathrm{~nm}$. The latter are both unsafe, because for $\sigma_{a}=3 \mathrm{~nm}$ the generalized distribution gives a collision probability $2.75 \times 10^{-6} / \mathrm{nm}$ and for $\sigma_{a}=5 \mathrm{~nm}$ it gives $3.58 \times 10^{-5} / \mathrm{nm}$ and both significant exceed the ICAO ATLS.

\subsection{Lateral separation in controlled airspace}

In controlled airspace the lateral separation (53a) is reduced to (54a):

$$
L_{b}=5 \mathrm{~nm}, \quad \sigma_{b}=0.05,0.1,0.2,0.3,0.4,0.5,1.0 \mathrm{~nm},
$$

and the r.m.s. position errors considered (54b) are correspondingly smaller than (53b). Again the generalized distribution meets the ICAO ATLS for a r.m.s. deviation $\sigma_{b} \leq 0.05 \mathrm{~nm}$ smaller than predicted by the Laplace $\left(\sigma_{b} \leq 0.2 \mathrm{~nm}\right)$ and Gaussian $\left(\sigma_{b} \leq 0.5 \mathrm{~nm}\right)$ distributions. For the safe r.m.s deviation $\sigma_{b}=0.05 \mathrm{~nm}$ the Gaussian probability of collision is negligible.

\begin{tabular}{|c|c|c|c|c|}
\hline \multicolumn{2}{|c|}{ Probability distribution } & Laplace & Gauss & Generalized \\
\hline quantity & $\sigma_{b}$ & $Q_{1 b}$ & $Q_{2 b}$ & $Q_{3 b}$ \\
\hline Unit & $\mathrm{nm}$ & - & - & - \\
\hline 1,0 & $\mathrm{~nm}$ & $2,42 \mathrm{E}-03$ & $5,45 \mathrm{E}-04$ & $3,80 \mathrm{E}-03$ \\
\hline 0,5 & $\mathrm{~nm}$ & $7,72 \mathrm{E}-06$ & $1,57 \mathrm{E}-11$ & $3,58 \mathrm{E}-04$ \\
\hline 0,4 & $\mathrm{~nm}$ & $3,47 \mathrm{E}-07$ & $1,91 \mathrm{E}-17$ & $1,28 \mathrm{E}-04$ \\
\hline 0,3 & $\mathrm{~nm}$ & $1,68 \mathrm{E}-09$ & $2,17 \mathrm{E}-30$ & $2,75 \mathrm{E}-05$ \\
\hline 0,2 & $\mathrm{~nm}$ & $2,84 \mathrm{E}-14$ & $9,77 \mathrm{E}-68$ & $1,92 \mathrm{E}-06$ \\
\hline 0,1 & $\mathrm{~nm}$ & $4,95 \mathrm{E}-29$ & $1,04 \mathrm{E}-270$ & $3,88 \mathrm{E}-09$ \\
\hline 0,05 & $\mathrm{~nm}$ & $3,84 \mathrm{E}-59$ & $0,00 \mathrm{E}-00$ & $4,70 \mathrm{E}-13$ \\
\hline
\end{tabular}

Table 2. Lateral $b$ CPC for the Laplace, Gaussian and generalized probabilities.

\subsection{Vertical separation in oceanic airspace}

The probabilities of vertical separation can be less upward than downward, due to gravity, proximity to the service ceiling, etc.; apart from this correction (Campos \& Marques, 2007, 2011), the preceding theory can be used with the standard vertical separation (55a):

$$
L_{c}=2000 \mathrm{ft}, \quad \sigma_{c}=40,50,100,200,300 \mathrm{ft},
$$

and r.m.s. deviations (55b). The r.m.s. height deviation that meets the ICAO ATLS is about $40 \mathrm{ft}$ according to the generalized distribution, with larger and unsafe predictions for the Laplace $(100 \mathrm{ft})$ and Gaussian $(200 \mathrm{ft})$ distributions. 


\begin{tabular}{|c|c||c|c|c|}
\hline \multicolumn{2}{|c||}{ Probability distribution } & Laplace & Gauss & Generalized \\
\hline Quantity & $\sigma_{c}$ & $Q_{1 c}$ & $Q_{2 c}$ & $Q_{3 c}$ \\
\hline Unit & $\mathrm{ft}$ & - & - & - \\
\hline 300 & $\mathrm{ft}$ & $9,88 \mathrm{E}-07$ & $4,68 \mathrm{E}-11$ & $4,03 \mathrm{E}-06$ \\
\hline 200 & $\mathrm{ft}$ & $1,93 \mathrm{E}-08$ & $9,79 \mathrm{E}-17$ & $8,76 \mathrm{E}-07$ \\
\hline 100 & $\mathrm{ft}$ & $5,39 \mathrm{E}-14$ & $1,05 \mathrm{E}-48$ & $2,11 \mathrm{E}-08$ \\
\hline 50 & $\mathrm{ft}$ & $1,10 \mathrm{E}-25$ & $2,16 \mathrm{E}-178$ & $8,12 \mathrm{E}-11$ \\
\hline 40 & $\mathrm{ft}$ & $1,24 \mathrm{E}-31$ & $6,49 \mathrm{E}-276$ & $8,21 \mathrm{E}-12$ \\
\hline
\end{tabular}

Table 3. Vertical $a$ CPC for the Laplace, Gaussian and generalized probabilities.

\subsection{Reduced vertical separation}

The RSVM (Figure 5) introduced by Eurocontrol in upper European air space halves the vertical separation (56a) to (58a):

$$
L_{d}=1000 \mathrm{ft}, \quad \sigma_{d}=15,50,100,150 \mathrm{ft},
$$

and the r.m.s. position errors are correspondingly reduced from (56b) to (58b) in Table 4.

\begin{tabular}{|c|c||c|c|c|}
\hline \multicolumn{2}{|c||}{ Probability distribution } & Laplace & Gauss & Generalized \\
\hline quantity & $\sigma_{d}$ & $Q_{1 d}$ & $Q_{1 d}$ & $Q_{3 d}$ \\
\hline Unit & $\mathrm{ft}$ & - & - & - \\
\hline \hline 150 & $\mathrm{ft}$ & $1,98 \mathrm{E}-06$ & $1,87 \mathrm{E}-10$ & $8,05 \mathrm{E}-06$ \\
\hline 100 & $\mathrm{ft}$ & $3,86 \mathrm{E}-08$ & $3,92 \mathrm{E}-16$ & $1,71 \mathrm{E}-06$ \\
\hline 50 & $\mathrm{ft}$ & $1,08 \mathrm{E}-13$ & $4,20 \mathrm{E}-48$ & $4,04 \mathrm{E}-08$ \\
\hline 15 & $\mathrm{ft}$ & $2,55 \mathrm{E}-41$ & $0,00 \mathrm{E}-00$ & $6,86 \mathrm{E}-13$ \\
\hline
\end{tabular}

Table 4. Vertical $b$ CPC for the Laplace, Gaussian and generalized probabilities.

Taking as reference the generalized distribution to meet the ICAO ATLS: (i) the RVSM from $2000 \mathrm{ft}$ (Table 3) to $1000 \mathrm{ft}$ (Table 4) requires a reduction in r.m.s. altitude error from $40 \mathrm{ft}$ to $15 \mathrm{ft}$; (ii) the reduction of lateral separation from $50 \mathrm{~nm}$ in transoceanic (Table 1) to $5 \mathrm{~nm}$ in controlled (Table 2) airspace required a reduction of r.m.s. deviation from 0.5 to $0.05 \mathrm{~nm}$.

\section{Discussion}

The separation-position accuracy or technology-capacity trade-off was made for an air corridor ATM scenario with aircraft flying along the same flight path (Figure 2) or on parallel flight paths (Figure 1) with a constant separation. The generalized probability distribution leads to lower values of the r.m.s. deviation to meet the ICAO TLS, than the Laplace and Gaussian. Although the latter distributions are simpler, they underestimated 
the collision risk, and do not yield safe predictions. Using simultaneously lateral and vertical separations leads to much lower collision probabilities, and allows reducing each separation for the same overall safety. In the case of aircraft flying on parallel tracks, it is desirable to use alternate directions of flight (Figure 5), because: (i) adjacent flight paths correspond to aircraft flying in opposite directions, which spend less time close to each other, reducing the collision probability (Campos \& Marques, 2002; Eurocontrol, 1988; Reich, 1966); (ii) the aircraft which spend more time 'close' by are on a parallel track at twice the separation $2 \mathrm{~L}$, thus allowing a larger r.m.s. position error $\sigma$ for the same safety. If the aircraft have both altitude and lateral separation, and the two position errors are statistically independent, the ICAO ATLS is $\sqrt{8 \times 10^{-12}} / n m \approx 2.8 \times 10^{-6} / n m$ in each direction. For transoceanic flight this is met by a lateral r.m.s. deviation $\sigma_{l} \leq 3 \mathrm{~nm}$; for flight in controlled airspace with RVSM the ICAO ATLS wold be met with lateral $\sigma_{l} \leq 0.2 \mathrm{~nm}$ and altitude $\sigma_{h} \leq 150 \mathrm{ft}$ r.m.s. deviations. Using also along track or longitudinal separation adds a third dimension, requiring a smaller ICAO ATLS $\sqrt[3]{8 \times 10^{-12}} / \mathrm{nm}=2 \times 10^{-4} / \mathrm{nm}$ and allowing larger r.m.s. deviations in three directions.

\section{References}

Abramowitz, M. \& I., Stegun, (1965), Tables of Mathematical Functions, Dover.

Anderson, E.W., (1966), The Principles of Navigation, Hollis \& Carter.

Barnett, A. (2000), Free Flight and En-route Air Safety a First-order Analysis, Operations Research, Vol. 48, pp. (833-845).

Bousson, K., (2008), Model predictive control approach to global air collision avoidance, Aircraft Engineering and Aerospace Technology, Vol. 80, (6), pp. (605-612).

Campos, L.M.B.C., (1984), On the Influence of Atmospheric Disturbances on Aircraft Aerodynamics, Aeronautical Journal, June/July, pp. (257-264).

Campos, L.M.B.C., (1986), On the Aircraft Flight Performance in a Perturbed Atmosphere, Aeronautical Journal, Paper 1305, Oct., pp. (301-312).

Campos, L.M.B.C., (1997), On the Non-linear Longitudinal Stability of Symmetrical Aircraft, Journal of Aircraft, Vol. 36, pp. (360-369).

Campos, L.M.B.C., (2001), On the probability of Collision Between Aircraft with Dissimilar Position Errors, Journal of Aircraft, 38, pp. (593-599).

Campos, L.M.B.C. \& Marques, J.M.G., (2002), On Safety Metrics Related to Aircraft Separation, Journal of Navigation, Vol. 55, pp. (39-63).

Campos, L.M.B.C. \& Marques, J.M.G., (2004a), On the Combination of the Gamma and Generalized Error Distribution With Application to Aircraft Flight Path Deviation, Communications in Statistics-Theory and Methods, Vol. 33, No10, pp. (2307-2332).

Campos, L.M.B.C. \& Marques, J.M.G., (2004b), On Wake Vortex Response for All Combinations of Five Classes of Aircraft, Aeronautical Journal, June, pp. (295310).

Campos, L.M.B.C. \& Marques, J.M.G. (2007) On the Probability of Collision Between Climbing and Descending Aircraft, Journal of Aircraft, Vol. 44 (2), pp. (550-557).

Campos, L.M.B.C. \& Marques, J.M.G., (2011), On the Probability of Collision for Crossing, Aircraft Eng. Aerospace Technology (to appear). 
Etkin, B., (1981), The Turbulent Wind and its Effects on Flight, Journal of Aircraft, Vol. 18, $\mathrm{N}^{\mathrm{0}} 5$.

Etkin, B. \& Reid, L.D., (1996), Dynamics of Flight: Stability and Control, Wiley.

Etkin, B. \& Etkin, D.A., (1990), Critical Aspects of Trajectory Prediction Flight in a nonUniform Wind, Agardograph AG-301, Vol.1.

Eurocontrol, (1988), European Studies of Vertical Separation Above FL290 - Summary Report, Brussels, Oct.

Eurocontrol, (1998), Air Traffic Management Strategy for 2000+, November.

Eurocontrol, (2000), Objective Measures of ATM System: Safety Metrics, C-Integra Report to Eurocontrol.

FAA, (2011), Aeronautical Information Manual (AIM), Official Guide to Basic Flight Information and ATC Procedures.

Goursat, E., (1950), Course of Analysis, Dover.

Houck, S. \& Powell, J.D., (2001), Assessment of Probability of Mid-air Collision During an Ultra Closely Spaced PParallel Approach, AIAA Paper 2001-4205.

International Civil Aviation Organization, (2005), Air Traffic Services, Annex 11.

International Civil Aviation Organization, (2006), Rules of the Air, Annex 2.

International Civil Aviation Organization, (2007), Procedures for Air Traffic Management, Doc 4444.

Johnson, N.L. \& Balakrishnan, N., (1995), Continuous Univariate Probability Distributions, Wiley 1995.

Mises, R.V., (1960), Theory of Probability and Statistics, Academic Press.

Nassar, M.M., Khamis, S.M. \& Radwan, S.S., (2011), On Bayesian sample size determination, Journal of Applied Statistics, Vol. 38, (5), pp. (1045-1054).

Reich, P.G., (1966), Analysis of Long-range Air Traffic Systems: Separation Standards. Journal of Navigation, №19, pp. (88-98), pp. (169-186), pp. (331-347).

Reiss, R.D. \& Thomas, M., (2001), Statistical Analysis of Extreme Values. Birkhauser Verlag.

Rossow, V.J., (1999), Lift-generated Vortex Wakes of Subsonic Transport Aircraft, Progress in Aerospace Sciences, Vol. 35, pp. (507-660).

Shortle, J.F., Xie, Y., Chen, C.H. \& Dunohue, G.L., (2004), Simulating Collision Probabilities of Landing Airplanes at Non-towered Airports. Simulation, No80, pp. (21-31).

Shortle, J.F., Zhang, Y., Wang, J., (2010), Statistical Characteristics of Aircraft Arrival Tracks, Journal of the Transportation Research Board, Vol. 2177, pp. (98-104).

Spalart, P.R., (1998), Airplane Trailing Vortices. Annual Review of Fluid Mechanics, No30, pp. (107-138).

Vismari, L.F. \& Júnior, J.B.C., (2011), A Safety Assessment Methodology Applied to CNS/ATM-Based Air Traffic Control System, Reliability Engineering $\mathcal{E}$ System Safety, Vol. 96, pp. (727-738) .

Whittaker, E.T. \& Watson, G.N., (1927), Course of Modern Analysis, Cambridge University Press. 
Yuling, Q. \& Songchen, H., (2010), A Method to Calculate the Collision Risk on Air-Route, Management and Service Science (MASS), Proceedings of IEEE International Conference.

Zhang, Y. \& Shortle, J., (2010), Comparison of Arrival Tracks at Different Airports, Proceedings of $4^{\text {th }}$ International Conference on Research in Air Transportation ICRAT 2010, Budapest Hungary, June $01-04$. 


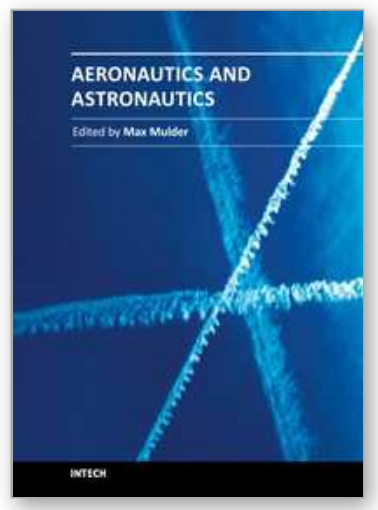

\author{
Aeronautics and Astronautics \\ Edited by Prof. Max Mulder
}

ISBN 978-953-307-473-3

Hard cover, 610 pages

Publisher InTech

Published online 12, September, 2011

Published in print edition September, 2011

In its first centennial, aerospace has matured from a pioneering activity to an indispensable enabler of our daily life activities. In the next twenty to thirty years, aerospace will face a tremendous challenge - the development of flying objects that do not depend on fossil fuels. The twenty-three chapters in this book capture some of the new technologies and methods that are currently being developed to enable sustainable air transport and space flight. It clearly illustrates the multi-disciplinary character of aerospace engineering, and the fact that the challenges of air transportation and space missions continue to call for the most innovative solutions and daring concepts.

\title{
How to reference
}

In order to correctly reference this scholarly work, feel free to copy and paste the following:

Luis Campos and Joaquim Marques (2011). Collision Probabilities, Aircraft Separation and Airways Safety, Aeronautics and Astronautics, Prof. Max Mulder (Ed.), ISBN: 978-953-307-473-3, InTech, Available from: http://www.intechopen.com/books/aeronautics-and-astronautics/collision-probabilities-aircraft-separation-andairways-safety

\section{INTECH}

open science | open minds

\section{InTech Europe}

University Campus STeP Ri Slavka Krautzeka 83/A 51000 Rijeka, Croatia Phone: +385 (51) 770447 Fax: +385 (51) 686166 www.intechopen.com

\section{InTech China}

Unit 405, Office Block, Hotel Equatorial Shanghai No.65, Yan An Road (West), Shanghai, 200040, China 中国上海市延安西路65号上海国际贵都大饭店办公楼 405 单元 Phone: +86-21-62489820

Fax: $+86-21-62489821$ 
(C) 2011 The Author(s). Licensee IntechOpen. This chapter is distributed under the terms of the Creative Commons Attribution-NonCommercialShareAlike-3.0 License, which permits use, distribution and reproduction for non-commercial purposes, provided the original is properly cited and derivative works building on this content are distributed under the same license. 